\title{
Impact of an Educational Program on Improving Nurses Knowledge and Practice Concerning Caring for Neonates with Respiratory Distress Syndrome
}

\author{
Mahasen K. Ahmed ${ }^{1}$, Nafisa H. Refat ${ }^{2}$, Nora A. Zaki ${ }^{3}$ \& Etemad H. Sayed ${ }^{4}$. \\ ${ }^{1 .}$ Nursing Specialist At Police Hospital in Assuit, Neonatal Intensive Care Unit, Egypt. \\ 2. Professor of Pediatrics, Faculty of Medicine, Assuit University, Egypt. \\ 3. Assistant Professor of Pediatric Nursing, Faculty of Nursing, Assuit University, Egypt. \\ ${ }^{4 .}$ Lecture of Pediatric Nursing, Faculty of Nursing, Assuit University, Egypt.
}

\begin{abstract}
Respiratory distress syndrome in neonates reported with $60 \%-70 \%$ mortality rates. Aim of the study was to develop, apply and evaluate an educational program for nurses to improve their knowledge and practice about care of neonates with respiratory distress syndrome. Study design a quasi- experimental study design was used to conduct this study. Subjects and methods: the study was carried out in the neonatal intensive care unit at Assuit police hospital. Sample composed of 50nurses. Two tools were used to collect necessary data .1. A structured interview questionnaire was used to assess nurses' knowledge regarding respiratory distress syndrome. 2. An observational checklist to assess nurses' practice regarding their care provided for neonates. Results: This study revealed that mean knowledge and practice score were much higher in the post program implementation $9.58 \pm 1.43,293.64 \pm 7.51$ respectively compared to preprogram $6 \pm 1.88,166.1 \pm 29.22$ respectively. At follow up phase the mean knowledge and practice score were slightly decreased to $8.1 \pm 1.95,251.04 \pm 10.36$. Conclusion: Statistically significant improvement was revealed in total knowledge and practice. These scores were much higher in the post program implementation compared to pre- program and slightly decline in the follow up phase. Recommendation: Educational program is needed for updating nurses' knowledge and improving their practice.
\end{abstract}

\section{Keyword: Educational Program, Nurses Knowledge And Practice \& Neonatal Respiratory Distress Syndrome (NRDS)}

\section{Introduction}

Respiratory distress syndrome appears immediately after birth or within 4 hours. It is characterized by tachypnea (>60 breaths/min), intercostal and subcostal retractions, nasal flaring, grunting, and cyanosis in room air. Tachypnea is due to an attempt to increase minute ventilation to compensate for a decreased tidal volume and increased dead space. Retractions occur as the infant is forced to generate a high intrathoracic pressure to expand the poorly compliant lungs. Grunting results from the partial closure of the glottis during forced expiration Other clinical features may include hypotension, acidosis and hyperkalemia (Aversa, et al., 2016).

Neonatal respiratory distress syndrome affects about $1 \%$ of newborn infants and is the leading cause of death in preterm infants. The incidence decreases with advancing gestational age, from about $50 \%$ in babies born at 26-28 weeks, to about $25 \%$ at $30-31$ weeks. Newborn respiratory distress occurs in about 7\% of deliveries. (Schraufnagel, 2010)

The most common causes of respiratory distress in newborns are transient tachypnea of the newborn, respiratory distress syndrome, meconium aspiration syndrome, pneumonia, sepsis, pneumothorax, and delayed transition. Rare causes include choanal atresia; diaphragmatic hernia; trachea-esophageal fistula, congenital heart disease, neurologic, metabolic, and hematologic disorders (Edward, et al., 2013).

Acute complications include air leaks and intracranial hemorrhage. Long-term complications: respiratory distress syndrome has been associated with an increased incidence of chronic lung disease, and neurologic impairment (poggi \& Dani, 2014).

Treatment of neonatal respiratory distress should be both generalized and disease-specific, and follow updated neonatal resuscitation protocols. Oxygenation can be maintained by delivering oxygen via bag/mask, nasal cannula, oxygen hood, nasal continuous positive airway pressure, or ventilator support. Resuscitation with $100 \%$ oxygen may increase neonatal mortality compared with ambient air. Blended oxygen, with the fraction of inspired oxygen ranging from $21 \%$ to $50 \%$ oxygen, stabilizes premature newborns, and pulse oximetry monitors are used to maintain saturations around 90\%. (Wong, 2015) 
Adequate fluid and electrolyte balance should be maintained. Oral feedings are withheld if the respiratory rate exceeds 60 respirations per minute to prevent aspiration. A neutral thermal environment reduces the newborn's energy requirements and oxygen consumption. If the illness exceeds the clinician's expertise and comfort level or the diagnosis is unclear in a critically ill newborn, neonatologist should be consulted (Huybrechts, et al., 2015).

Nurses play an important role in caring for neonates with respiratory distress syndrome including physical examination, count respiratory rate and watch for grunting, assess the severity of respiratory distress syndrome. The nurse carefully assess the infant's respiratory status to determine the degree of respiratory distress, assess the infant's cardiac rate \& rhythm; count the apical pulse for one minute, note if irregularities in the rate or bounding pulses, also observing the infant's general activity and promoting adequate gas exchange, additionally the nurse should prepare emergency equipments available for use in the event of cardiac or respiratory arrest (Kliegman, et al., 2011).

Nurses also have a key role in the care of neonate with respiratory distress syndrome to decrease neonatal mortality and morbidity. Nursing management for neonates with respiratory distress syndrome through assist in newborn's endotracial intubation, maintain mechanical ventilation as indicated, measure oxygen concentration, continuous monitoring of the $\mathrm{SaO} 2$, observe the infant's response to oxygen. Suctioning as needed because the gag reflex is weak and cough is ineffective. Moreover, promoting adequate nutrition and hydration is important (Osadnik,et al , 2017).

\section{Significance of the study}

Respiratory distress syndrome in neonates reported with $60 \%-70 \%$ mortality rates, this condition makes infant difficult to breathe. (Luis, et al, 2012). So that, this study would be done to assess nurses' knowledge ,practice and design, implement and evaluate an educational program regarding care of neonates with respiratory distress syndrome in the neonatal intensive care unit (NICU) at Assuit police hospital.

\section{Aim of the study}

The aim of this study was to:

- Assess nurses' knowledge and practice regarding their care provided for neonates with respiratory distress syndrome in the neonatal intensive care unit of Assiut police hospital.

- Develop, apply and evaluate an educational program for nurses based on their needs to improve their knowledge and practice about care of neonates with respiratory distress syndrome.

\section{Research hypothesis}

Nurses' knowledge and practice concerning care of neonates with respiratory distress syndrome will be improved after applying the educational program.

\section{Subjects \& Method}

\section{Research design}

A quasi-experimental research design was used in this study.

Setting

The study was conducted at the neonatal intensive care unit in Assuit police hospital, Egypt.

\section{C-Sampling}

All nurses working at the neonatal intensive care unit in Assiut police hospital were included in the study. Total number was (50) nurses regardless of their age, years of experience or qualification. They divided into baccalaureate (17) diploma of nursing (23) and technical of nursing (10).

\section{3- Tools of the study}

Two tools were designed to collect the necessary data as follow

Tool I: Structured interview questionnaire sheet.

This tool was developed by the researcher based on relevant literature and it consisted of two parts:

Part one: Socio-demographic characteristics of studied participants

It included socio-demographic characteristics of the studied participants as (age, sex, marital status, level of education, occupation, years of experiences, and attending training courses about care of neonates with respiratory distress syndrome.

Part two: Knowledge of studied participants regarding respiratory distress syndrome. Nurses knowledge about care given to the neonates with respiratory distress syndrome at the neonatal intensive care unit in Assiut police hospital. This part includes 7 questions about definition of neonatal respiratory distress syndrome, causes, risk factors, signs and symptoms, treatment and nursing care plan for neonatal respiratory distress syndrome.

Scoring system of nurses' knowledge was developed by the researcher. The total grade of knowledge equal 14 grades, each correct answer took 2 grades, incorrect answer took zero (Bowden \& Greenberg, 2012). The total knowledge score was classified as:

Satisfactory: $60 \%$ and more

Unsatisfactory $<60 \%$

Tool II: Observation check list

Observational checklist which was developed by the researcher after revised extensive literature to assess the practice of studied participants through direct observation. They included the following procedures: hand washing (12) steps, , taking vital signs, taking an axillary 
temperature(14) steps, taking an apical pulse(10) steps, taking respiratory rate(9) steps, suctioning(21) steps, mouth care (6) steps, positioning (7) steps, oxygen therapy (10) steps, intravenous therapy (34) steps, naso gastric tube feeding (24) steps, oral feeding (21) steps. Two grades were given for the item which done correctly, one for done incorrectly and zero for not doing, so total grades of practices were (336) for (168) observational steps.

Scoring system of nurses' practice was developed by the researcher. The total grade of practice equal 366 grades. Each step done correctly scored 2, done incorrectly scored 1 grade and not done scored zero grade. (Ball, et al., 2012)

The total score was classified as

Competent $60 \%$ and more

Incompetent less than $60 \%$

Methods

An official letter was obtained from the dean of the faculty of nursing, Assiut university to directorate of Assuit police hospital for approval to collect data and apply for a particular educational program, after an explanation of the aim of the study.

\section{Ethical consideration}

1. The research was approved from the dean of the faculty of nursing.

2. There was no risk for studied participants during application of the research.

3. Witten consents were obtained from the studied participants that were willing to participate in the study, after explaining the nature and aim of the study.

4. The studied participants were assured that the data of this research was used only for the research purpose.

5. Confidentiality and anonymity assured.

\section{Pilot study}

A pilot study was carried out on (10\%) of studied participants to assess tools clarity, applicability and to estimate the time needed to fulfill each sheet. Validity

The validity of the study tool was assessed to check the revalence, coverage, and clarity of questions by a jury panel of professors from five experts in nursing and medicine to ascertain their content validity. The validity was $95 \%$.

\section{Reliability}

Reliability analysis was done for each tool; Tool I ( $\mathbf{0 .}$ 789) and tool II (0.810) by using Cronbach s' Alpha test.

The program development

On the basis of the results of pilot study, the program was designed and prepared by the researcher after reviewing of related literature.

\section{Field work}

- The field work was carried out through a period of 8 months starting from March 2016 to October 2016, with approximately 280 hours divided in 80 hours theoretical and 200 hours practical, nurses were divided into 10 small groups each group has 1-5 nurses.

- Before the application of the program, the researcher introduced herself to participants in order to establish the necessary rapport and gain their attention and interest, and to explain the purpose of the program, its objectives and benefits.

- A pretest was conducted to the nurses at the neonatal intensive care unit in Assuit police hospital for their knowledge using tool I. Each nurse was observed separately to complete the observational checklist using tool II.

Implementation of the program

The actual work started by meeting the nurses throughout the morning shift, the researcher first introduced herself to nurses and gave them a complete background about the study and its aim, then the pretest format, pre- designed by the researchers in Arabic language, was distributed in order to collect the required data.

An educational program about care of neonate with respiratory distress syndrome was implemented for nurses in the form of scheduled session as well as on the teaching during their official working hours. There was a total of 10 sessions. These were repeated ten times to each subgroup of 1-5 nurses. The duration of each session was variable, and ranged between 60 and 90 minutes, including 15 minutes for discussion and feedback, and 15 minutes for break. Each subgroup was given the freedom to choose their optimal time for receiving the program whenever they have minimal workload. Each participant obtained a copy of the program booklet that included all training material and procedures such as hand washing, vital signs, oxygen therapy, suctioning, nasogastric tube feeding and intravenous therapy. Each session usually started by a summary of what has been taught during the preceding sessions, and the objectives of the new one. Reinforcement techniques, such as giving praise to the interested nurses, were used for motivation during program implementation.

\section{Evaluation of the program}

The researcher used a questionnaire and observational check lists to evaluate the outcomes of the program which used to evaluate knowledge and practice respectively through pre and posttests immediately after implementation of the program and after three months as follow up test for each studied participant . 


\section{Difficulties of the study}

- It was difficult to recruit all nurses at the same time to attend the program sessions. So, nurses were divided into subgroups that could attend the program by choosing the time of least workloads. In cases of missing a subject by a nurse, the researcher resorted to repeating what had been missed to that nurse separately prior to the following session.

- Increased number of admission to the unit with decrease number of nurses so a lot of time was lost at the neonatal intensive care unit without training any nurse.

\section{Administration Design}

Meeting with nursing supervisors and physicians of the neonatal intensive care unit to explain the objectives and contents of the program and the methods for applying the program helped to gain their cooperation and to allow the release of nurses to attend the program during minimal workload activities.

Complete confidentiality of any obtained information was ensured.

\section{Statistical analysis}

The data were tested for normality using the Anderson-Darling test and for homogeneity variances prior to further statistical analysis. Categorical variables were described by number and percent $(\mathrm{N}, \%)$, where continuous variables described by mean and standard deviation (Mean, SD). Chi-square test and fisher exact test used to compare between categorical variables where compare between continuous variables by t-test land ANOVA TEST. A two-tailed $p<0.05$ was considered statistically significant. We are Used person Correlation to Appear the Association between scores.All analyses were performed with the IBM SPSS 20.0 software.

\section{Results}

Table (1): Socio demographic characteristics of the studied nurses $(n=50)$.

\begin{tabular}{|c|c|c|}
\hline Variable & $(\mathbf{n}=50)$ & $\%$ \\
\hline \multicolumn{3}{|l|}{ Age in years } \\
\hline $20-$ & 29 & 58.0 \\
\hline $30-$ & 18 & 36.0 \\
\hline$\geq 40$ & 3 & 6.0 \\
\hline Mean \pm SD(range) & \multicolumn{2}{|c|}{$29.2 \pm 6.2(210-43)$} \\
\hline \multicolumn{3}{|l|}{ Gender } \\
\hline Male & 9 & 18.0 \\
\hline Female & 41 & 82.0 \\
\hline \multicolumn{3}{|l|}{ Educational Level } \\
\hline Bachelor of Nursing & 17 & 34.0 \\
\hline Nursing Health and Nursing institute & 11 & 22.0 \\
\hline Nursing Diploma & 22 & 44.0 \\
\hline \multicolumn{3}{|l|}{ Years of experience: } \\
\hline$<5$ & 17 & 34.0 \\
\hline $5<10$ & 11 & 22.0 \\
\hline$\geq 10$ & 22 & 44.0 \\
\hline Mean \pm SD(range) & \multicolumn{2}{|c|}{$10.3 \pm 6.9(1-23)$} \\
\hline \multicolumn{3}{|l|}{ Attending training courses: } \\
\hline Yes & 15 & 30.0 \\
\hline No & 35 & 70.0 \\
\hline
\end{tabular}


Table (2): Nurses' correct knowledge about neonatal respiratory distress syndrome through the program phases (pre, post and follow up $(n=50)$

\begin{tabular}{|c|c|c|c|c|c|c|c|}
\hline \multirow{2}{*}{ Variable } & \multicolumn{2}{|c|}{ Pre } & \multicolumn{2}{|c|}{ Post } & \multicolumn{2}{|c|}{ Follow up } & \multirow{2}{*}{ P. value } \\
\hline & No & $\%$ & No & $\%$ & No & $\%$ & \\
\hline $\begin{array}{l}\text { Definition of neonatal respiratory distress } \\
\text { syndrome }\end{array}$ & 44 & 88.0 & 50 & 100.0 & 47 & 94.0 & $0.041^{*}$ \\
\hline $\begin{array}{l}\text { Causes of neonatal respiratory distress } \\
\text { syndrome }\end{array}$ & 26 & 52.0 & 49 & 98.0 & 37 & 74.0 & $<0.001 * *$ \\
\hline $\begin{array}{l}\text { Signs and symptoms of neonatal } \\
\text { respiratory distress syndrome }\end{array}$ & 19 & 38.0 & 34 & 68.0 & 31 & 62.0 & $0.006 * *$ \\
\hline $\begin{array}{l}\text { Complication of neonatal respiratory } \\
\text { distress syndrome }\end{array}$ & 27 & 54.0 & 39 & 78.0 & 32 & 64.0 & $0.040^{*}$ \\
\hline $\begin{array}{l}\text { Treatment of neonatal respiratory distress } \\
\text { syndrome }\end{array}$ & 37 & 74.0 & 48 & 96.0 & 40 & 80.0 & $0.010^{*}$ \\
\hline $\begin{array}{l}\text { Nursing care of neonate with respiratory } \\
\text { distress syndrome }\end{array}$ & 9 & 18.0 & 25 & 50.0 & 23 & 46.0 & $0.002 * *$ \\
\hline
\end{tabular}

- Chi-square test, $*$ Significant difference at $p$. value $<0.05, * *$ Significant difference at $p$. value $<0.01$

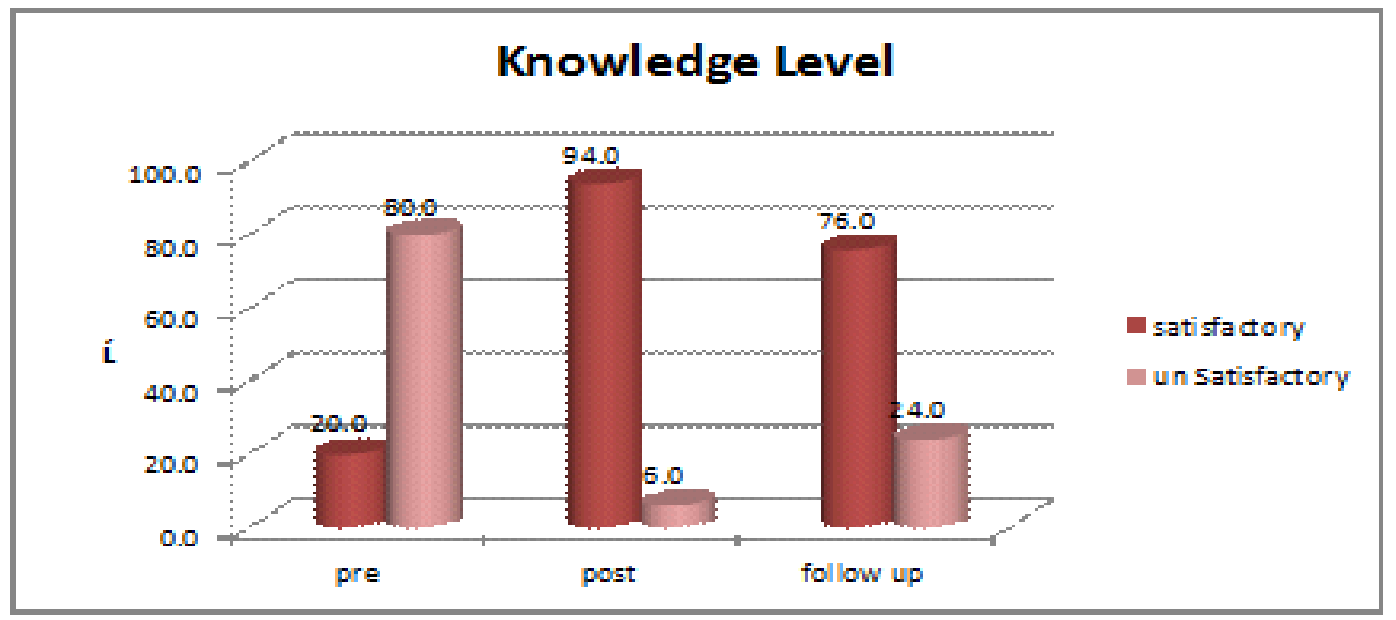

Figure (1) knowledge level about neonatal respiratory distress syndrome during program phases pre-post and follow up.

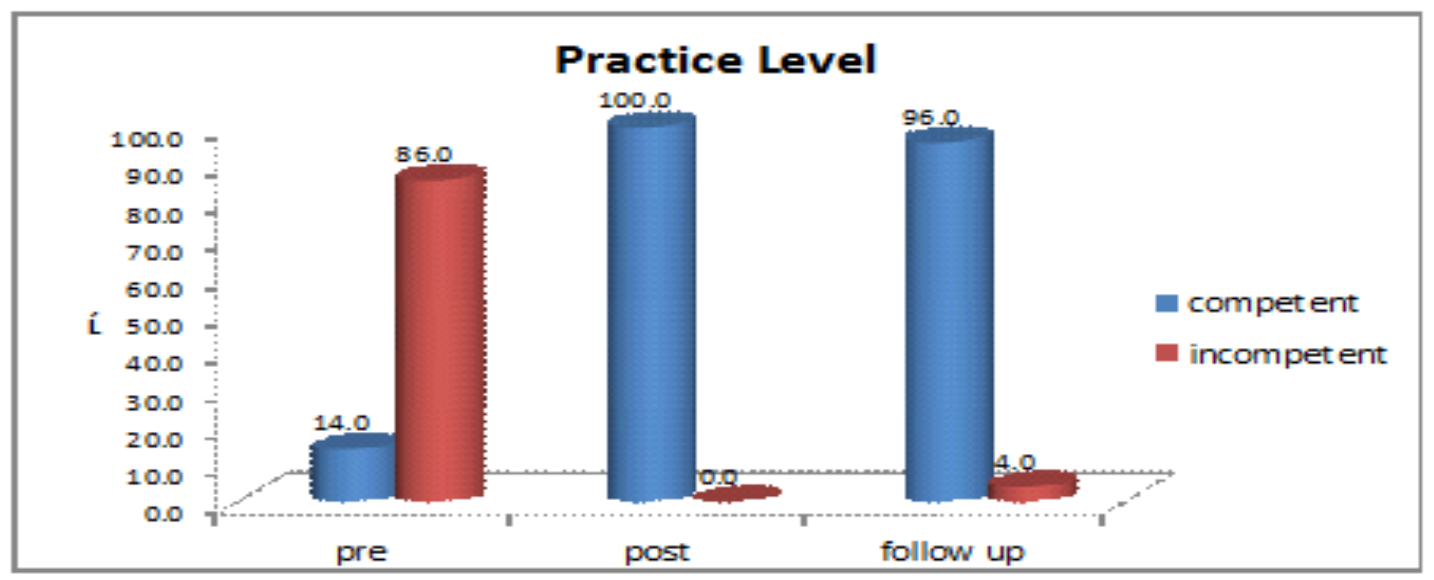

Figure (2) Total nurses' Practice about neonatal respiratory distress syndrome throughout intervention program phases (pre, post and follow-up) 
Table (3): Comparison between mean score of nurses' practice about care of neonates with respiratory distress syndrome throughout intervention program phases (pre, post and follow-up).

\begin{tabular}{|l|c|c|c|c|}
\hline \multicolumn{1}{|c|}{ Variable } & Pre & Post & Follow up & P. value \\
\hline Hand washing & $15.26 \pm 2.83$ & $21.28 \pm 1.5$ & $17.14 \pm 2.26$ & $<0.001^{* *}$ \\
\hline Vital signs & $31.86 \pm 5.88$ & $59 \pm 2.21$ & $50.58 \pm 4.15$ & $<0.001^{* *}$ \\
\hline Suctioning & $19.46 \pm 4.34$ & $35.16 \pm 2.1$ & $30.78 \pm 1.52$ & $<0.001^{* *}$ \\
\hline Mouth care & $5.96 \pm 1.56$ & $11.3 \pm 0.95$ & $9.88 \pm 0.98$ & $<0.001^{* *}$ \\
\hline Positioning/ Semi-setting position & $5.68 \pm 1.48$ & $12.72 \pm 1.23$ & $10.56 \pm 1.25$ & $<0.001^{* *}$ \\
\hline Oxygen therapy & $8.46 \pm 2.64$ & $16.74 \pm 1.7$ & $13.72 \pm 1.63$ & $<0.001^{* *}$ \\
\hline Intravenous Therapy & $34.12 \pm 4.42$ & $59.68 \pm 2.61$ & $51.36 \pm 1.37$ & $<0.001^{* *}$ \\
\hline Nasogastric tube feeding & $24.18 \pm 5.8$ & $40.98 \pm 2.02$ & $34.72 \pm 2.19$ & $<0.001^{* *}$ \\
\hline Oral Feeding & $21.12 \pm 5.5$ & $36.78 \pm 2.15$ & $32.3 \pm 3.3$ & $<0.001^{* *}$ \\
\hline Total Practice score & $\mathbf{1 6 6 . 1} \pm \mathbf{2 9 . 2 2}$ & $\mathbf{2 9 3 . 6 4 \pm 7 . 5 1}$ & $\mathbf{2 5 1 . 0 4 \pm 1 0 . 3 6}$ & $<\mathbf{0 . 0 0 1} * *$ \\
\hline
\end{tabular}

- ANOVA TEST, ** Significant difference at p. value $<0.01$

Table (4): Relation between mean scores of nurses' knowledge and practices throughout intervention program phases.

\begin{tabular}{|l|c|c|c|c|}
\hline \multicolumn{1}{|c|}{ Group } & $\begin{array}{c}\text { Knowledge } \\
\text { Mean } \pm \text { SD }\end{array}$ & $\begin{array}{c}\text { Practice score } \\
\text { Mean } \pm \text { SD }\end{array}$ & T-test & P. value \\
\hline Pre & $6 \pm 1.88$ & $166.1 \pm 29.22$ & -0.183 & 0.203 \\
\hline Post & $9.58 \pm 1.43$ & $293.64 \pm 7.51$ & 0.103 & 0.475 \\
\hline Follow up & $8.1 \pm 1.95$ & $251.04 \pm 10.36$ & 0.295 & $0.038^{*}$ \\
\hline
\end{tabular}

* Statistically significant relation at $p$. value $<0.05$

* Statistically significant relation at $p$. value $<0.05$

In relations to socio-demographic characteristics Table (1): Clarified that more than half $(58.0 \%)$ their ages ranged from 20 years to less than 30 years and only $(6 \%)$ of them were 40 years and more. According to their gender. It was found that the majority $82 \%$ of them were female regarding the educational level it was reported that about $(44 \%)$ of them had diploma and $34 \%$ of them had bachelor degree. This table also illustrated that $44 \%$ of the studied nurses their years of experiences were more than 10 years. Regarding their attendance for training program. It was observed that $70 \%$ of nurses had not attended any training program.

Table (2): Clarified that most of the studied nurses $(88.0 \%)$ had satisfactory knowledge about definition of neonatal respiratory distress syndrome, while in relation to when did suction catheter should be changed, causes and complication of neonatal respiratory distress syndrome, it was found that $50.0 \%, 52.0 \%$ and $54.0 \%$ of them had unsatisfactory knowledge respectively, this table also illustrated that $74.0 \%$ of the studied nurses had unsatisfactory knowledge regarding treatment of neonatal respiratory distress syndrome while only $18.0 \%$ of the studied nurses had unsatisfactory knowledge regarding to nursing care of neonates with respiratory distress syndrome and this percentage increased to become $50.0 \%$ after the educational program slightly decline to $46 \%$ during follow up phase. $46 \%$ of the studied nurses had unsatisfactory knowledge regarding signs, symptoms and regarding suitable position should during suctioning and increased to be $100 \%, 64 \%$ after the educational program respectively.(figure1)

Table (3): Presented comparison between mean score of nurses' practice regarding care of neonatal respiratory distress throughout intervention program phases pre-post and follow up. It indicates an increase in the practice scores post program phase. However, this increase reached statistical significance for nurses basic practice about (hand washing, vital signs , suctioning mouth care positioning - oxygen therapy, intravenous therapy, nasogastric tube feeding $(\mathrm{p}<0.01)$ practice scores demonstrated some declines after three months at follow up testing. Never less the scores were still higher than the preprogram baseline scores

Table (4): Demonstrated the relation between total scores of nurses' knowledge and practices throughout intervention program phases. Relation was found between total score of nurses knowledge and practice post program and follow up. The mean knowledge and practice score were much higher in the post program implementation $9.58 \pm 1.43,293.64 \pm 7.51$ respectively compared to preprogram $6 \pm 1.88$, $166.1 \pm 29.22$ respectively. At follow up phase the 
mean knowledge and practice score were slightly decreased to $8.1 \pm 1.95,251.04 \pm 10.36$ respectively the result was statistically significant $\mathrm{P}<0.01$ for both total practice scores and total knowledge score.

Figure (2): As regards the nurses' practice for their actual care to neonates with respiratory distress syndrome figure 2 reported that only $14 \%$ of the studied nurses had competent level of practice and $86 \%$ had incompetent practice pre the educational program. After the educational program the competence level of practice for studied nurses reached to $100 \%$ and this competence practice decrease slightly to reach $96 \%$ during follow up phase of the educational program.

\section{Discussion}

Respiratory distress syndrome is one of the most common reason for admission to the neonatal intensive care unit. $15 \%$ of term infants and $29 \%$ of late preterm infants admitted to the neonatal intensive care unit because of significant respiratory morbidity. (Edwards, et al., 2013). The course of illness with RDS depends on the size and gestational age of the baby, the severity of the disease, the presence of infection; whether or not the baby needs mechanical help to breathe. RDS typically worsens over the first 48 to 72 hours (Dorothy, et al., 2010). So that, the current study aimed to assess nurses' knowledge, practice and develop, apply and evaluate an educational program regarding their care provided for neonates with respiratory distress syndrome in the neonatal intensive care unit of Assuit police hospital.

As regards the sociodemographic characteristics of the studied participants. The results of the present study revealed that more than half of nurses their ages ranged from 20 years to less than 30 years and nearly half of them had diploma nursing education these findings in an agreement with (Elsayed, et al., 2013) who assessed nursing care provided for neonates with respiratory distress syndrome in the neonatal intensive care units at Makkah Al-Mukarramah in Saudi Arabia stated that more than half of nurses their ages ranged from 20 years to less than 30 years .While this result disagree with (AbdAlrhman, 2015) who assessed nurses knowledge and practice regarding infection control in operating room at main Assuit university and (Khalifa, 2011) who stated that more than half of nurses were less than twenty five years old. Regarding the attendance of nurses for training programs the present study revealed that the majority of nurses weren't attending any training program about care of neonates with respiratory distress syndrome this might be attributed to that there isn't enough time to attend educational program, another possible explanation the hospital didn't establish training program regarding neonatal respiratory distress syndrome these finding contradicted with (Aita \& Goulet, 2009) who assessed assessment of neonatal nurses' behaviors that prevent overstimulation in preterm infants who stated that nurses should be exposed to training programs to raise their awareness and the training programs should be regularly updated in view of changing knowledge and work practice. While these findings were agreed with (Abd Raboo, et al., 2013) and (Mohamed, 2016) who assessed Assessment of nurses knowledge and practices about suctioning in the neonatal intensive care unit Assuit university hospital who stated that the majority of the studied nurses hadn't attend any training courses. As regard years of experience it was noticed that the majority of nurses had experience of ten years and more these results agreed with (Mahmoud \& Hani (2017) who found that the majority of the nurses had ten or more years of experience.

According to the present study findings before the educational program, nurses had unsatisfactory knowledge about neonatal respiratory distress syndrome this was indicated by their low scores, these findings were similar with the study findings of (Elsayed, et al., 2013) who assessed nurses' knowledge about care given to neonates with respiratory distress syndrome in Makkah Almokarramah in Saudi Arabia. This unsatisfactory baseline knowledge noticed among nurses might be attributed to that after graduation nurses stop reading and neglect updating their professional knowledge, another possible reason might be the absence of any resources or programs for continued nursing education that are essential to upgrade and improve nurses knowledge during their care for neonates with respiratory distress syndrome. The total knowledge level become satisfactory after application of the educational program. During follow up test after three months have shown. Some declines but they were still higher.

Regarding to comparison between mean score of nurses' practice regarding care of neonatal respiratory distress throughout intervention program phases prepost and follow up .Nurses practice throughout intervention program phases pre- post and follow up .It was found that level of practice was incompetent at all practices except hand washing pre intervention program and became competent after intervention program and follow up. These findings are in the same line with (Parajulee, 2011) who assessed the nurses knowledge and performance about care given to newborn in the NICU and concluded that there was lack in nurses practice for care given to newborn in NICU.

Concerning the total score level of nurses' practice about their actual care provided for neonates with 
RDS in the NICU. The present study findings points to high percentage of nurses with incompetent practice level before implementation of the program, thus the majority of nurses had incorrect actions related to the principles of infection control such as hand washing and wear gloves this might be attributed to lack of nurses knowledge about infection control precautions. These findings were agreed with the study findings of (parajulee, 2011) who assessed the nurses knowledge and practice about care given to newborn in NICU and concluded that there was lack in nurses practice for care given to newborn in NICU. And mismatched with that (Elbokhary et al., 2015) who found in their research in Khartoum teaching hospital ICU that more than two thirds of nurses had fair practice level about endotracheal suctioning.

Regarding to relation between nurses knowledge and practice throughout program phases. There is statistically significant improvement in total knowledge and practice, mean knowledge and practice score were much higher in the post program implementation at the follow up the mean knowledge and practice score were slightly decreased, this unsatisfactory baseline knowledge noticed among nurses might be attributed to that after the educational program nurses abandon reading and neglect updating their professional knowledge another possible reason might be the absence of any resources or programs for continued nursing education that are essential to improve nurses knowledge during their care for neonates with respiratory distress syndrome .The result was statistically significant at $\mathrm{P}$ value $\mathrm{P}<0.05$ for total practice scores and total knowledge scores.

\section{Conclusion}

The current study concluded that: Statistically significant improvement was revealed in total knowledge and practice. The mean knowledge and practice scores were much higher in the post program implementation compared to pre- program and slightly decline in the follow up phase

\section{Recommendations}

Based on the findings of the current study the researchers recommended the followings:

* Nurses working in the NICUs need periodical training program to improve their knowledge and performance about care of neonates with RDS.

* Standardized nursing procedures and guidelines should be available to guide the nurses in dealing with high risk neonates in the NICUs.

* Providing updating booklets, pamphlets and boosters for nurses to upgrade their knowledge about neonatal RDS.
* Further studies should be conducted to improve nurses' knowledge and performance regarding care of neonates with RDS in the NICUs in Assiut police hospital.

\section{References}

1. Abd Raboo A., Marzouq A., labeb A., \& Amary H., (2013): Impact of poisoning training program on nurses knowledge and practices at emergency unit at Assuit University.

2. Abdel Rahman S., (2015): Assessment of nurses knowledge and practice regarding Infection control in Operating Room at main Assuit University and Aleman Hospital. Thesis in adults Nursing, Faculty of Nursing, Assuit University , 82-90.

3. Aita, M., \& Goulet, C., (2009): Assessment of Neonatal Nurses' Behaviors that Prevent Overstimulation in Preterm Infants. Retrieved on November 17,2012 . Accessed Oct, 2013 Retrieved from http://www.ncbi.nlm.nih.gov/pubmed/127067.

4. Aversa S., Marseglia L., \& Manti S., (2016): "Ventilation strategies for preventing oxidative stress-induced injury in preterm infants with respiratory disease: an update," Paediatric Respiratory Reviews, vol. 17, pp. 71-79, 2016.

5. Ball J., Bindler R., \& Cowen K., (2012): Clinical skills manual for principles of pediatric nursing :caring for children $\left(5^{\text {th }} \mathrm{Ed}\right)$. USA. Julie Levin Alexander publisher. pp. 6467,72-75,134-137.

6. Bowden V., \& Greenberg S., (2012): Pediatric Nursing procedures $\left(3^{\text {rd }}\right.$ Ed) . Philadelphia, PA: Lippincott Williams \&wilkins.pp.68-72,188-193,322-326,450-457.

7. Dorothy, R., Marlow, B., \& Redding, A., (2010): Textbook of Pediatric Nursing,20thed, W.B. Saunders Company. PP: 504-516.

8. Edwards M., Kotecha S., \& Kotecha S., (2013): Respiratory distress of the term newborn infant. Paediatr Respir Rev;14(1):2936

9. Elbokhary R., Osam A., \&Al-khader M., (2015): Knowledge and practice of ICU nurses regarding Endotracheal Suctioning for Mechanically Ventilated patients in Khartoum teaching Hospital, Faculty of Nursing, Sudan International University, Khartoum.

10. Elsayed A., El Nagger N., \& Sahar M., (2013): Nursing care provided for neonates with respiratory distress syndrome in the neonatal intensive care units at Makhah Elmokaramah in Saudia Arabia thesis in 
pediatric nursing, faculty of nursing Ain Shams university, Cairo

11. Huybrechts K., Bateman B., \&Palmsten K., (2015): Antidepressant use late in pregnancy and risk of persistent pulmonary hypertension of the newborn. JAMA. 2015;313(21):2142215.

12. Khalifa H., (2011): Assessment of nurses' performance regarding reducing or preventing of nosocomial infection for patients with cancer. Master degree in medical surgical nursing, faculty of nursing, Assuit University.

13. Kliegman R., Behrman R., Geme J., Stanton B., \& Schornf, (2011): Nelson text book of pediatrics, Saunders EISEVIER, USA 19th ed chap 96 pp. 610-11

14. Luis J., Luis D., Samuel F., \&Gabriel, C., (2012): Recommendations to Improve Healthcare of Neonates with Respiratory Insufficiency Beneficiaries of Seguro Popular. Public de México, 54, (1).

15. Mahmoud S., \& Hani M., (2017): Assessment of Nurse's Knowledge and Practice Working in District Hospitals at Minia Governorate about Neonatal Hyperbilirubinemia. Iosrjournals, 6(2): 9-16.

16. Mohamed K., (2016): Assessment of nurses knowledge and practices about suctioning in the neonatal intensive care unit Assuit university Hospital, Thesis in pediatric nursing. Faculty of nursing. Assuit university 72-80.

17. Osadnik, C., Tee, V., Carson, Chahhoud, K., Picot, J., Wedzicha, J., \& Smith, B., (2017): Non, invasive ventilation for the management of acute hypercapnia respiratory failure due to exacerbation of the chronic obstructive pulmonary disease. Cochrane Database of Systemic Reviews, (7)

18. Parajulee, S., (2011): Assess Knowledge of Nurses Towards Cardio-Pulmonary Resuscitation in NICU at Bharatpur Nepal University Hospital. Degree Master of Medical Sciences Bharatpur, Nepal University, pp.: 7680.

19. Poggi C., \&Dani C., (2014): “Antioxidant strategies and respiratory disease of the preterm newborn: an update," Oxidative Medicine and Cellular Longevity, vol. 2014, no. 36, Article ID 721043, 10 pages.

20. Schraufnagel D., (2010): Respiratory distress syndrome. Breathing in America: Diseases, Progress, and Hope. New York, NY: American Thoracic Society; 2010:197-205.
21. Wong's (2015): Nursing care of infant and children. Mosby, Inc., an affiliate of Elsevier Inc, Canda 10th ed chap 8, Pp 313-. 